\title{
ECT is superior to pharmacotherapy for the short-term treatment of medication-resistant inpatients with bipolar depression
}

\section{Axel Nordenskjöld}

School of Health and Medical Sciences, Örebro University, Örebro, Sweden; axel.nordenskjold@orebroll.se

ABSTRACT FROM: Schoeyen HK, Kessler U, Andreassen OA, et al. Treatment-resistant bipolar depression: a randomized controlled trial of electroconvulsive therapy versus algorithm-based pharmacological treatment. Am J Psychiatry 2015;172:41-51.

\section{WHAT IS ALREADY KNOWN ON THIS TOPIC}

Within 1-4 years, about one-fourth of stable patients with bipolar disorder suffer from depression despite prophylactic lithium therapy. ${ }^{1}$ Electroconvulsive therapy (ECT) is equally effective for unipolar and bipolar depression, ${ }^{2}$ however, the rate of use of ECT varies considerably between countries, ${ }^{3}$ and, in clinical guidelines, ECT is often considered only after multiple pharmacological agents have been tried. ${ }^{4}$ This is probably due to the paucity of randomised studies directly comparing the effects of pharmacotherapy and ECT for bipolar depression. Moreover, it remains unclear whether the memory impairments seen in some patients treated with ECT are attributable to the disease or to the treatment.

\section{METHODS OF THE STUDY}

This Norwegian multicentre randomised trial enrolled 73 inpatients suffering from bipolar depression. The two treatment arms were as follows: 6 weeks of algorithm-based pharmacotherapy without ECT versus unilateral ECT followed by pharmacotherapy. During their lifetime, patients should have already tried a minimum of two medications (antidepressants, lithium, lamotrigine, quetiapine or olanzapine) without response. Substance abuse and high suicide risk were two of the exclusion criteria. Opaque envelopes ensured allocation concealment from the computer-generated random-number sequence. During the study, the treating psychiatrist and patient were not blind to the treatment allocation, but the rating sessions were recorded and ratings were confirmed by a masked rater.

\section{WHAT DOES THIS PAPER ADD?}

- ECT was significantly more effective than pharmacotherapy, with a mean difference in baseline to 6 -week change of 6.6 points $195 \%$ Cl 2.5 to 10.6) on the Montgomery-Åsberg Depression Rating Scale (MADRS). Correspondingly, the response rate was higher in the ECT group $(74 \%$ vs $35 \%)$; however, the difference in remission rate $(35 \%$ vs $30 \%$ ) was not statistically significant.

- Both treatments were well tolerated (only three patients discontinued in each group).

- Interestingly, there was no difference in the frequency of memory disturbance (two patients in each group).

\section{LIMITATIONS}

- The patients were inpatients at enrolment, thus, the study is not automatically informative regarding the relative efficacy of ECT and pharmacotherapy in outpatients who may have less severe or less episodic symptoms. Furthermore, it is unclear if the results are generalisable to bipolar patients with substance abuse.

- Possibly, the exclusive use of unilateral ECT may have decreased the efficacy of the ECT arm. But of greater importance, the exclusion of suicidal patients and patients too ill to consent to randomisation is likely to have decreased the relative difference in efficacy, as such patients are more likely to benefit from ECT than from pharmacotherapy.

- This was a 6-week study, and therefore not indicative of long-term outcomes of either memory or depression.
- Furthermore, $38 \%$ of the randomised patients did not return to the hospital after discharge to participate in the final 6-week assessment within the required time frame.

\section{WHAT IS NEXT IN RESEARCH?}

A replication of the study is important to confirm these findings with pharmacotherapy-resistant hospitalised bipolar patients, and meta-analysis may be used to possibly further narrow the $\mathrm{Cl}$ for the relative efficacy of the treatments. Randomised studies offer unique opportunities to differentiate the effects of the treatment and the disease. An earlier report from the same trial showed no difference in general neurocognitive function, but there were indications of reduced consistency in autobiographical memory a few weeks after treatment. ${ }^{5}$ Therefore, a long-term follow-up study of this patient sample should compare the relative effects on cognition and memory. Moreover, it remains to be established if and how long these initial benefits can be maintained with some combination of pharmacotherapy and/or continuation of ECT.

\section{DO THESE RESULTS CHANGE YOUR PRACTICES...AND WHY?}

Following this study, patients should be informed about the superior efficacy of ECT as compared to pharmacotherapy, for the acute treatment of inpatients with medication-resistant bipolar depression, and patients should have their preferred treatment. For this to become a reality, ECT needs to be available in hospitals that treat bipolar patients. This represents a change of practice in many countries where the availability of ECT is currently limited. This study also strengthens the argument for a more prominent place for ECT in international guidelines for the treatment of severe bipolar depression.

Open Access This is an Open Access article distributed in accordance with the Creative Commons Attribution Non Commercial (CC BY-NC 4.0) license, which permits others to distribute, remix, adapt, build upon this work non-commercially, and license their derivative works on different terms, provided the original work is properly cited and the use is non-commercial. See: http://creativecommons.org/licenses/by-nc/4.0/

Competing interests None declared. doi:10.1136/eb-2015-102069

Received 11 June 2015; Revised 29 June 2015; Accepted 26 August 2015

\section{REFERENCES}

1. Geddes JR, Burgess S, Hawton K, et al. Long-term lithium therapy for bipolar disorder: systematic review and meta-analysis of randomized controlled trials. Am J Psychiatry 2004;161:217-22.

2. Dierckx B, Heijnen WT, van den Broek WW, et al. Efficacy of electroconvulsive therapy in bipolar versus unipolar major depression: a meta-analysis. Bipolar Disord 2012;14:146-50.

3. Leiknes KA, Jarosh-von Schweder L, Hoie B. Contemporary use and practice of electroconvulsive therapy worldwide. Brain Behav 2012;2:283-344.

4. Grunze H, Vieta E, Goodwin GM, et al. The World Federation of Societies of Biological Psychiatry (WFSBP) Guidelines for the biological treatment of bipolar disorders: update 2010 on the treatment of acute bipolar depression. World J Biol Psychiatry 2010;11:81-109.

5. Kessler U, Schoeyen HK, Andreassen OA, et al. The effect of electroconvulsive therapy on neurocognitive function in treatment-resistant bipolar disorder depression. J Clin Psychiatry 2014;75:e1306-13. 